\title{
Bio-functionalization of a novel biocompatible high entropy alloy used for bone implants
}

\author{
Mirela M. Codescu ${ }^{1}$, Alina Vladescu ${ }^{2,3 *}$, Victor Geanta ${ }^{4}$, Ionelia Voiculescu ${ }^{4 *}$, Iulian Pana ${ }^{2}$, Mihaela Dinu $^{2}$, \\ Adrian E. Kiss ${ }^{2}$, Viorel Braic ${ }^{2}$, Delia Patroi ${ }^{1}$, Virgil E. Marinescu${ }^{1}$, Mihai Iordoc ${ }^{1}$ \\ 1 R\&D National Institute for Electrical Engineering ICPE-CA Bucharest; mirela.codescu@icpe-ca.ro; de- \\ lia.patroi@icpe-ca.ro; virgil.marinescu@icpe-ca.ro; mihai.iordoc@icpe-ca.ro \\ 2 National Institute for Research and Development for Optoelectronics INOE2000, 409 Atomistilor St., \\ Magurele-Bucharest, Romania; alinava@inoe.ro; iulian.pana@inoe.ro; mihaela.dinu@inoe.ro; \\ kadremil@yahoo.com; viorel.braic@inoe.ro \\ 3 National Research Tomsk Polytechnic University, Physical Materials Science and Composite Materials \\ Centre, Research School of Chemistry \& Applied Biomedical Sciences, 43 Lenin Avenue, 634050, Tomsk, \\ Russia; alinava@inoe.ro \\ 4 University Politehnica of Bucharest, Splaiul Independentei 313, Bucharest 060042, Romania; \\ victorgeanta@yahoo.com; ioneliav@yahoo.co.uk \\ * Correspondence: A.V. - alinava@inoe.ro; Tel.+4.021.457.57.59:; I.V. - ioneliav@yahoo.co.uk
}

\begin{abstract}
In this paper, a novel biocompatible alloy defined as FeMoTaTiZr was obtained and functionalized by hydroxyapatite-based coatings (HAP) in order to increase their biocompatibility, bioactivity, and resistance to corrosion for to be used as bone implants. To obtain the surface with antibacterial properties, the HAP coatings were doped with small amount of Zn. The alloy was prepared using the VAR (Vacuum Arc Remelting) equipment, while the coatings by RF magnetron sputtering method. The EDS analysis confirmed the presence of $\mathrm{Ca}$ and $\mathrm{P}$ in the case of all developed coatings, having $\mathrm{Ca} / \mathrm{P}$ or $\mathrm{Ca} /(\mathrm{P}+\mathrm{Zn})$ ratio of about 1.70 and 1.66 , respectively. The XRD and ATR-FTIR investigations confirmed the presence of calcium phosphate phases. The roughness of uncoated substrates increased after coating with HAP, and it was considerably increased by the $\mathrm{Zn}$ addition. The electrochemical tests showed that the un-doped HAP exhibited good corrosion behavior, while Zn doped HAP coatings have a high dissolution rate in fetal bovine serum, being more proper as a biodegradable material.
\end{abstract}

Keywords: VAR alloy obtaining; Biomedical applications; Apatite films; Corrosion, X-ray method, Electron microscopy; Hardness.

\section{Introduction}

High entropy alloys (HEA) proposed by Yeh and Miracle [1,2] are a new class of metallic materials characterized by chemical composition that contains at least 5 different elements, in equiatomic percent. In order to be appropriate for biomedical applications, the high entropy alloys must contain just elements that are considered biocompatible, such as: $\mathrm{Ti}, \mathrm{Zr}, \mathrm{Ta}, \mathrm{Mg}$, $\mathrm{Ca}, \mathrm{Zn}$, Si etc. Other elements with low toxicity such as $\mathrm{Mo}$ and $\mathrm{Fe}$, are currently used for to obtain biocompatible alloys [3-6].

Currently, there is a wide variety of high entropy alloys that can be used in different fields, due to their special and specific properties, including industrial, aeronautical, military, medical applications and so on [7-9]. The high entropy alloys from the FeMoTaTiZr alloying system can be used for the manufacture of medical devices, human prosthesis, and implants. Iron plays a central role in the hemoglobin molecules formation and in the transport of oxygen. Human tissues contain $50 \mathrm{ppm}$ of bound iron, especially hemoglobin, myoglobin, and various cytochrome enzyme systems. Iron is toxic only for high level contents. It is released through oxidation processes and 
it does not accumulate in tissues being metabolized [10]. Molybdenum is an element with a low toxicity and it is essential for the human body. It is added in metallic alloys to grains refinement, to improve the mechanical and chemical properties of solid solutions [11-13]. Metallic tantalum is a promising biomaterial whose applications have been limited for reasons of technical performance and not biological ones. Recent cell culture studies have related the good osteoblastic behavior of commercial pure tantalum. It can be used for a wide variety of clinical applications such as: joint replacement, reconstruction after tumor resection, necrotic treatment of the femoral head and spine [14-16]. Titanium is a non-toxic element for the human body, even in larger quantities. Titanium is used in medical applications for multiple specific fields, such as: orthopedics, cardiovascular surgery, ophthalmology, dentistry, urology, cosmetic surgery, neurology, suture material for wound healing, controlled drug delivery systems. The excellent biological behavior of titanium, its remarkable corrosion resistance and elasticity similar to human bone justify its increased use as a biomaterial and as a component of medical and dental devices [17,18]. Zirconium and zirconium alloys are used for medical applications, such as devices for the total replacement of the knee and hip, dentures, due to its excellent resistance to corrosion and wear provided by its dense and superficial adherent oxide layers $[19,20]$.

Metallic surfaces used in clinical practice for preparation of orthopaedic implants (hip, knees, shoulder, etc.), dental implants (orthodontic braces) or osteosynthesis devices (nails, screws, plates, rods etc.) or other medical tools used for long or short implantation (e.g. stents, pacemaker). One way or another, the metallic implants were enormously used in medical applications for many years, nonetheless these devices still have some disadvantages in clinical practice and they should be removed and replaced by a new implant. This process is stressful for patients due to the physical and emotional trauma. For example, in the case of dental and orthopaedic implants, the main disadvantage is related to the low bioactivity and osseoconductivity abilities $[21,22]$. The most common metallic materials used in biomedical applications are $\mathrm{Ti}$ based alloy (Ti6Al4V), stainless steel (316L), CoCr alloys [23]. It is worth mentioning that the challenge is to find proper material, which should combine various qualities such as: hardness, toughness, strength, biocompatibility, and wear or corrosion resistance, as well as good antibacterial capabilities [21,22,24-29]]. These requirements are difficult to find in one material. Thus, the research was turned to two directions: (a) to find an alloy with proper mechanical, strength, corrosion, and wear and fatigue resistant as well as nontoxic; and (b) to improve the alloy surface by coating in order to obtain the proper osseointegration and bioactive surfaces. Regarding the first point, there are a huge number of proposed alloys, most of these based on $\mathrm{Ti}[24,25,27-29]$. However, the research community proposed many medical implants made of novel obtained alloys, but none of these are approved by FDA yet (United States Food and Drug Administration), mainly caused by the concerns linked to biocompatibility $[24,30]$.

The goal of the present paper is to obtain novel biocompatible alloy with functionalized surfaces used for bone implants. For this purpose, FeMoTaTiZr high entropy alloy was obtained by VAR method, and then the functionalization of their surfaces, by depositing of two types of coatings based on hydroxyapatite (HAP), in order to increase their biocompatibility, bioactivity and resistance to corrosion. In order to also have the surface with antibacterial properties, the HAP coatings were doped with a small amount of $\mathrm{Zn}$. The content of $\mathrm{Zn}$ was selected based on the results reported by other researchers [31-34], who proved that a small amount of $\mathrm{Zn}$ is enough to assure the antibacterial properties. 


\section{Materials and Methods}

\subsection{Alloy preparation}

The recipe for the alloy in the FeMoTaTiZr system was designed by choosing the chemical elements that have the lowest possible bio-toxicity. Currently, some of these elements are used as an alloying base for the manufacture of medical devices. The new high entropy alloys based on FeMoTaTiZr system were obtained using the MRF ABJ 900 vacuum arc remelting equipment. The technological calculation for obtaining the alloy was performed for a weight of about $40 \mathrm{~g} / \mathrm{load}$, using raw materials with high purity (99.5\%).

The first step of the technological process was to obtain a pressure of $5 \times 10^{-3} \mathrm{mbar}$ in the vacuum chamber, followed by purging with argon (Ar 5.3 quality), 3 times, to reduce the oxygen concentration up to $60 \mathrm{ppm}$. Then, the smelting of the metallic materials was performed under an argon atmosphere (pressure of 1.2 bars), using an electric arc, with an intensity current of $450 \mathrm{~A}$. The melting was performed on both sides by the successive rotation of the mini-ingots, 8 times on each part, for a better homogenization of the chemical composition, due to the high melting temperature of the chemical elements used, as follows: $\mathrm{Fe}-1538^{\circ} \mathrm{C}$; Mo $-2623^{\circ} \mathrm{C}$; $\mathrm{Ta}-3017{ }^{\circ} \mathrm{C}$; $\mathrm{Ti}$ $1668^{\circ} \mathrm{C} ; \mathrm{Zr}-1855^{\circ} \mathrm{C}$. Figure 1 shows the mini-ingots of high entropy alloy and the samples prepared for metallurgical investigations and depositions (sanding with abrasive papers - Grit $320-1000$ and polishing with abrasive alpha alumina powders in suspension). EDX chemical analysis showed the following chemical compositions for FeMoTaTiZr alloy (masic \%): $\mathrm{Fe}=15.46 \% ; \mathrm{Mo}=20.45 \% ; \mathrm{Ta}=32.45 \% ; \mathrm{Ti}=12.67 \% ; \mathrm{Zr}$ $=18.97 \%$.

\section{FeMoTaTizr}

(a)

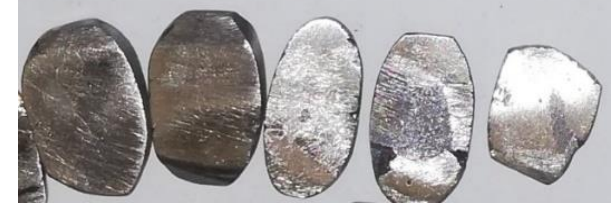

(b)

Figure 1. Mini-ingots (a) and samples cut for metallurgical investigation and depositions (b) from FeMoTaTiZr alloy.

\subsection{Coating's preparation}

The coatings were carried out using a RF magnetron sputtering technique with a system from Aja International Co (SUA). For the preparation of HAP, one cathode was used, made of HAP with $99.98 \%$ purity. For Zn based HAP coatings, two cathodes made of HAP and $\mathrm{ZnO}$ (99.98\% purity) were used. Because we intended to achieve coatings with slight quantities of $\mathrm{Zn}$ (considered as dopant), we used the cathode made of oxide $(\mathrm{ZnO})$, selected due to the comparable deposition rate with that of HAP. Prior to the deposition, substrates were pretreated as described in Refs. [22,35]. Deposition conditions of the coatings were listed in Table 1. These parameters were judiciously selected based on our previous results published in Refs. [35-42]. We also intended to obtain coatings with a thickness around $300 \mathrm{~nm}$. 
Table 1. Coating parameters values

\begin{tabular}{ccccccc}
\hline Coating type & $\begin{array}{c}\text { pbase } \\
\left(\times \mathbf{1 0}^{-4} \mathbf{P a}\right)\end{array}$ & $\begin{array}{c}\mathbf{p}_{\text {deposition }} \\
\left(\times \mathbf{1 0}^{-1} \mathbf{P a}\right)\end{array}$ & $\begin{array}{c}\mathbf{P}_{\mathrm{RF}}(\mathbf{W}) \\
\text { HAP }\end{array}$ & $\mathbf{Z n O}$ & $\mathrm{U}_{\text {bias }}(\mathbf{V})$ & $\mathbf{T}_{\text {deposition }}\left({ }^{\circ} \mathbf{C}\right)$ \\
HAP & 1.3 & 6.67 & 50 & - & -60 & 300 \\
HAP+Zn & & & 50 & 4 & & \\
\hline
\end{tabular}

*pbase - base pressure; pdeposition - Ar pressure; PRF - RF power fed on SiC cathode; Ubias - bias voltage; $\mathrm{T}_{\text {deposition }}$ - deposition temperature

\subsection{Methods for analysing}

Elemental composition of coatings was investigated using a scanning electron microscopy (SEM, Hitachi TM3030Plus), equipped with energy dispersive spectrometry (EDS, Bruker). The morphology of samples was performed using the field emission FESEM-FIB scanning electron microscope, Auriga type (Carl Zeiss SMT, Germany), with Gemini column for electrons beam. The XRD investigation of metallic uncoated substrate was done with an X-ray source $\mathrm{CuK}_{\alpha}$ radiation $(\lambda=1.5406 \AA)$ (Bruker, Germany), from $10^{\circ}$ to $100^{\circ}$, with a $1 \mathrm{D}$ LynxEye detector and a scan step size of $1 \mathrm{~s}$ per step and $0.040^{\circ}$ step size. After the indexing, the diffraction data was subjected to Rietveld refinement using TOPAS program. Phase composition of coatings was evidenced by grazing-incidence XRD (X-ray diffraction) using a $\mathrm{CuK}_{\alpha}$ radiation (SmartLab, Rigaku) from $20^{\circ}$ to $80^{\circ}$ with a step size of $0.02^{\circ} / \mathrm{min}$ and an incident angle of $2^{\circ}$.

The IR spectra of coatings were obtained using a FT-IR spectrometer (Jasco 6300), equipped with an ATR unit (Pike Technologies). A Si/ZnSe crystal was mounted in order to collect spectra in the $4000-550 \mathrm{~cm}^{-1}$ range at a spectral resolution of $4 \mathrm{~cm}^{-1}$. Before collecting any data, the ATR system was purged with a constant flow of nitrogen gas while the background and sample spectra were acquired using 150 average scans. The samples were placed directly on the surface of the Si/ZnSe crystal and a high-pressure clamp was further used to ensure a good spectral quality. After every single IR measurement, the crystal's surface was cleaned with isopropyl alcohol and the background spectrum was collected again.

The hardness and elastic modulus of the coatings were analysed using a Hysitron Premier TI nanoindentation system, equipped with a Berkovich indenter tip (100 nm radius). The $\mathrm{Z}$-axis calibration was executed using a standard calibration sample (fused quartz) with hardness ( $\mathrm{H}=9.25 \mathrm{GPa} \pm 10 \%$ ) and elastic modulus ( $\mathrm{E}=69.6 \mathrm{GPa} \pm$ $10 \%)$. For all experiments, a $10 \times 10 \mu \mathrm{m}^{2}$ area was previously scanned at a normal force of $2 \mu \mathrm{N}$ in order to examine the surface roughness. The indents were deliberately positioned at least $4 \mu \mathrm{m}$ apart from each other, whilst an applied force ranging from 1 to $10 \mathrm{mN}$ was engaged for each investigated coating. The hardness and reduced modulus values were both onward derived based on a similar model proposed in Ref. [43], which accounts for the mechanical parameters of the used substrate and thicknesses of the deposited films. Roughness of each investigated surface was evaluated by a profilometer (Dektak 150, Bruker) on ten line-scans, each one on a sliding length of $4000 \mu \mathrm{m}$. The main roughness parameters were evaluated: $\mathrm{R}_{a}-$ the 
arithmetic average of the roughness profile, and $S_{k}$ - skewness, according to the ISO 25178-601 standard [44].

The electrochemical measurements were performed with a VoltaLab 40 potentiostat/galvanostat, using a standard electrochemical cell, with 3 electrodes (reference electrode: $\mathrm{Ag} / \mathrm{AgCl}$; counter electrode: platinum) and a thermostat jacket. Because the samples had irregular shapes, they were trapped in system with a "platinum wire" and all surfaces, except the working one, were insulated with varnish. The electrochemical determinations were performed in fetal bovine serum to reproduce in vivo study conditions. All measurements were performed at room temperature and atmospheric pressure. The open circuit potential (OCP) measurements were performed for $10 \mathrm{~min}$ at the beginning and the end of the test, in order to observe the tendency of the passivating film in-situ occurred at the metal-electrolyte interface. The tests for variation of the polarization resistance and corrosion rate with the time were determined by the repetitive method of potential sweeping on an interval of $\pm 70 \mathrm{mV}$ around the equilibrium potential, tracing the polarization curves and calculating, by Stern method, the polarization resistance and corrosion rate for each time interval. The polarization curves were plotted in potentiodynamic regime on a range of $\pm 1000 \mathrm{mV}$ vs $\mathrm{Ag} / \mathrm{AgCl}$, at a potential scanning speed of $0.5 \mathrm{mV} / \mathrm{s}$.

\section{Results and discussions}

\subsection{Microstructures and composition of uncoated high entry alloy}

The SEM image of the FeMoTaTiZr alloy shown in Figure 2 reveals its structural inhomogeneity and it captures the demarcation area between the two regions: one, with a dendritic structure and the second region, with a fine textured structure, in which, even if there are still dendrites, they are of significantly reduced dimensions.

The inhomogeneous structures in terms of composition, as well as the appearance of microsegregations are phenomena that can occur in case of melting and solidification of high entropy alloys, due to the high content of main alloy components. The HEAs require to be several times re-melted in order to achieve ingots with chemical uniformity. Another difficulty consists in the differences of melting temperatures for the constituent elements that increase with the growing of the number of the alloy components. In order to avoid these negative aspects, for future experimental work, the manufacturing of the FeMoTaTiZr alloy will be performed starting from binary intermediate alloys, prepared by selection and association of the appropriate elements (considering the melting point criterion) [45].

The compositional chemical mapping of the analyzed area allows the understanding of the association of elements in the different investigated regions. Correlating these images with the EDS analysis (Figures 3 and 4), it can be concluded that the inhomogeneous zone contains mainly Mo undissolved in alloy, contaminated with oxygen (Figures 3, 4a and 4e). It can also be seen that the dendrites consist of an alloy containing Mo and Ta (Figures 3, 4a and 4f) and that they are dispersed in an 
alloy matrix containing Fe, $\mathrm{Zr}$ and $\mathrm{Ti}$ (Figures 3, 4b, 4c and 4d). The dark areas, in which no element is found in the elements distribution map, are pores.

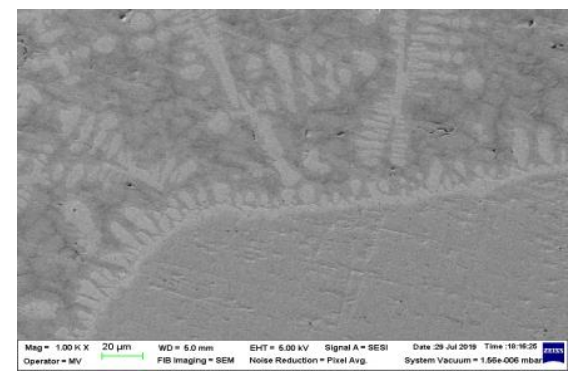

Figure 2. SEM image of FeMoTaTiZr alloy (x 1000).

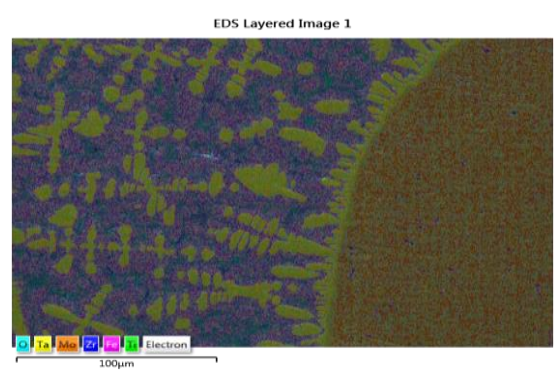

Figure 3. EDS image of FeMoTaTiZr multicomponent alloy.

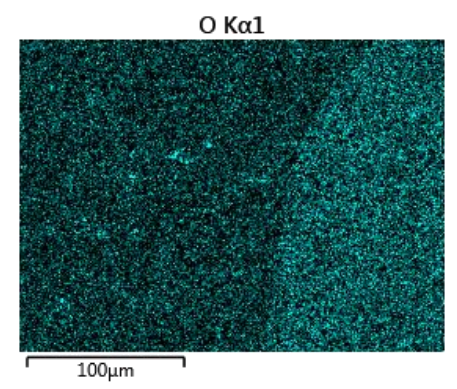

a)

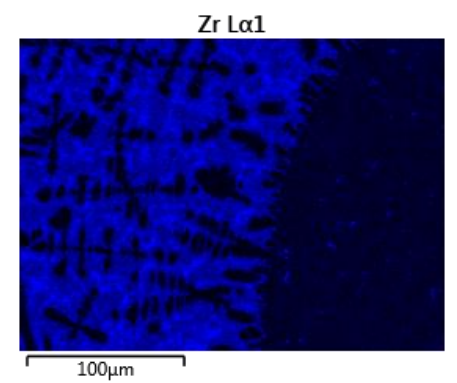

d)

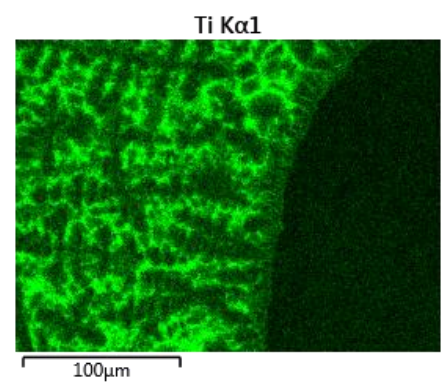

b)

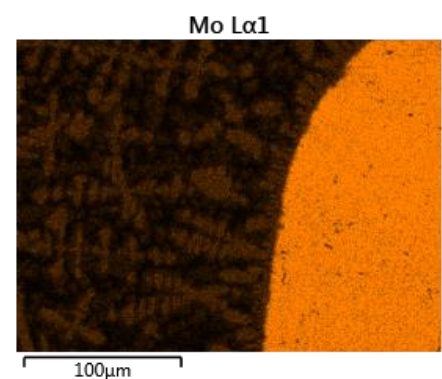

e)

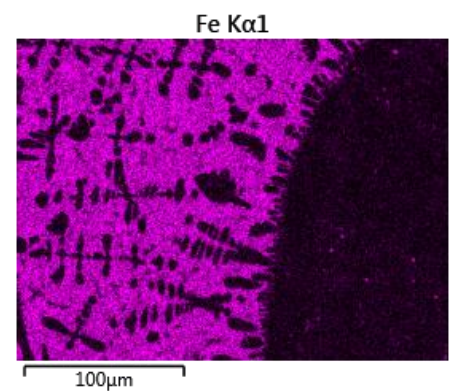

c)

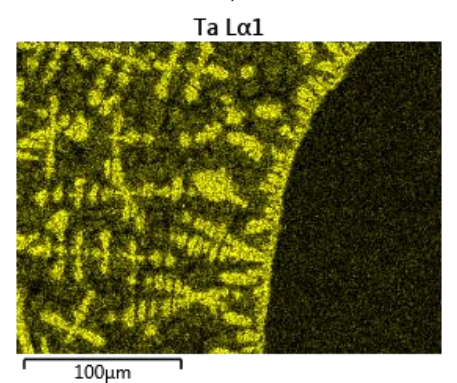

f)

Figure 4. The elemental distribution map for microstructure of FeMoTaTiZr multicomponent alloy:

a) O; b) Ti; c) Fe; d) Zr; e) Mo and f) Ta.

For the same region of the FeMoTaTiZr alloy, a quantitative analysis of the component elements was performed (Figures. 5a and 5b). Figure 5a shows the secondary electrons image of the multicomponent FeMoTaTiZr alloy, and Figure $5 \mathrm{~b}$ presents the semi quantitative composition spectra of the entire integrated area by elemental mapping for the same region of the investigated alloy. For the area integrated by elementary mapping (Figures 3 and 4 ) the composition of the alloy is (in wt. \%): $47.1 \% \mathrm{Mo} ; 17.2 \% \mathrm{Ta}$; $15.4 \% \mathrm{Zr} ; 9.6 \% \mathrm{Fe} ; 9.1 \% \mathrm{Ti}$ and $1.6 \% \mathrm{O}$. 


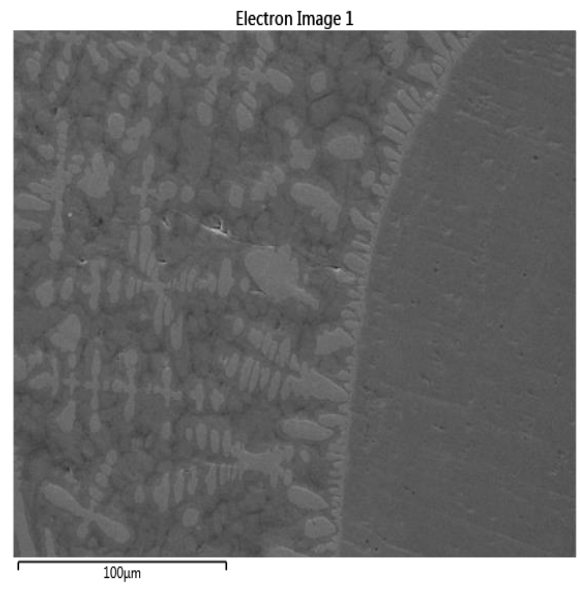

a)

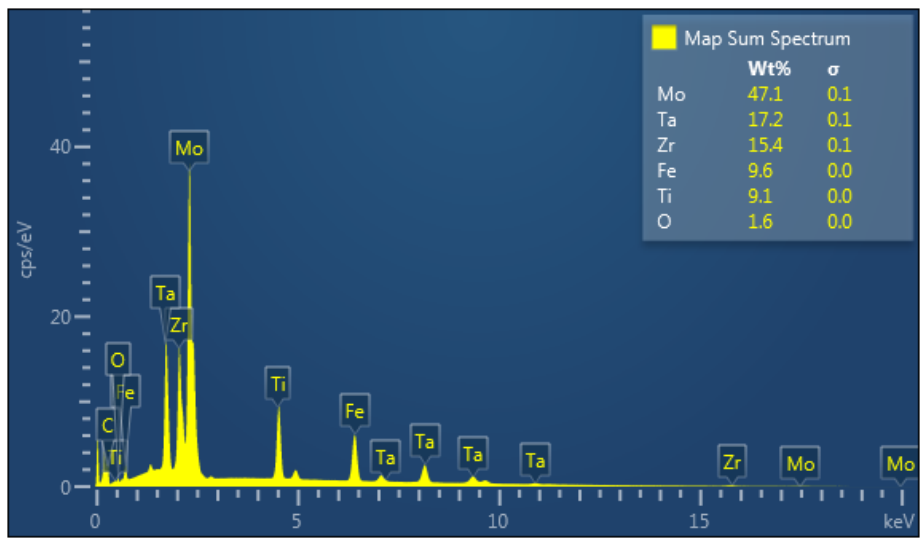

b)

Figure 5. The secondary electrons image a) and semi quantitative composition spectra of the entire integrated area by elemental mapping b) for the FeMoTaTiZr alloy.

The crystalline structure of FeMoTaTiZr alloy sample was analyzed through X-ray diffraction (Figure 6), the crystalline phases identification from the XRD pattern being done using the specific data base. The recorded peaks (Figure 6) reveal the presence of the following constituents: MoTa; $\mathrm{Mo},\left(\mathrm{Ti}_{7} \mathrm{Zr}_{3}\right){ }_{0.2} ; \mathrm{Ti}_{2} \mathrm{Fe}$ and $(\mathrm{FeMo}) \mathrm{Zr}$ (for this last phase, taking into account the elemental maps from Figures $4 \mathrm{c}-4 \mathrm{e}$, the iron is associated in alloy matrix with zirconium and not with molybdenum). The peaks are distinct, clear, their intensity allowing to appreciate the degree of crystallization of the constituents of studied alloy after casting. The most intense peak, at $2 \theta \sim 40^{\circ}$, belongs to the compound MoTa. Its presence confirms the results obtained by elemental mapping, regarding the composition of the dendrites in the case of the FeMoTaTiZr multicomponent alloy. The presence of the other two constituents, (Ti7 $\left.\mathrm{Zr}_{3}\right)_{0.2}$ at angle of $2 \theta$ $=34^{\circ}$ and $\mathrm{Ti}_{2} \mathrm{Fe}$ at angle of $2 \theta=41.5^{\circ}$, brings further clarifications concerning the matrix, in which the dendrites are arranged, namely the fact that it contains two constituents. The presence of Mo is explained by the fact that the melt was not homogenized during elaboration, which allowed that at solidification, a part of Mo, left undissolved, to solidify again (see the peak from the angle $2 \theta=40.5^{\circ}$ ).

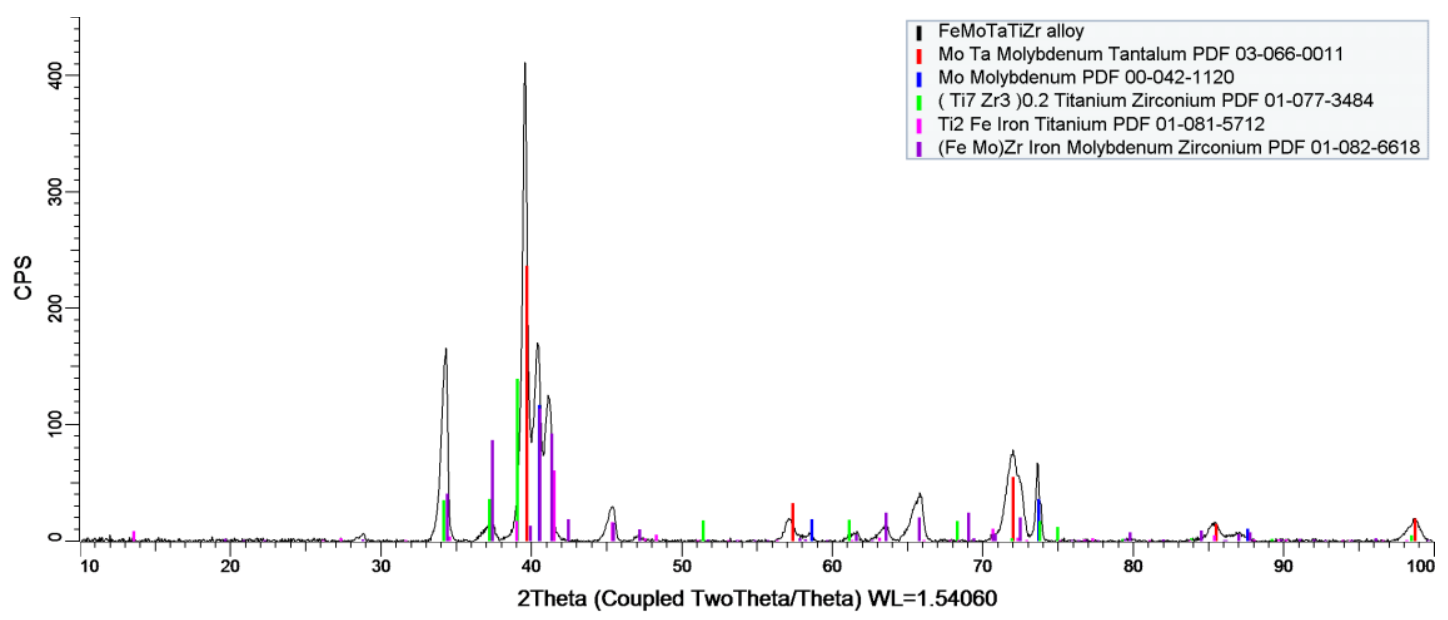

Figure 6. X-ray difractogram of the FeMoTaTiZr cast alloy. 


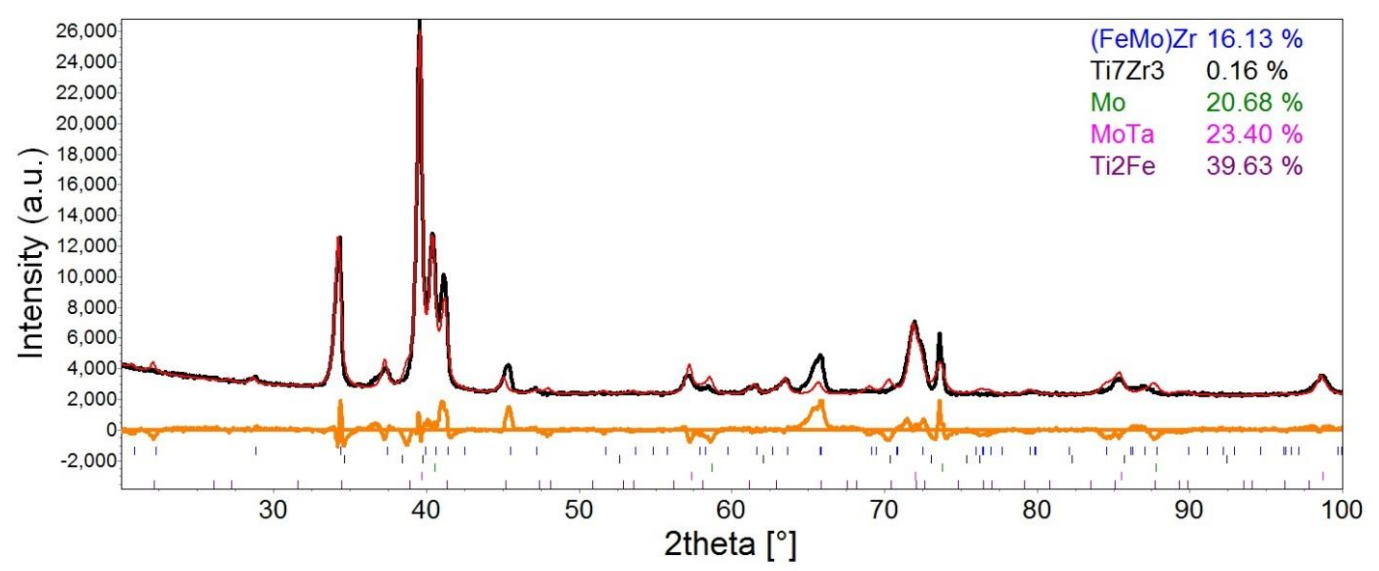

Figure 7. XRD Rietveld refinement results for FeMoTaTiZr cast alloy. The black and the red lines represent the observed and calculated intensities. Vertical bars mark positions for the Bragg reflections. Differences between the observed and calculated intensities are presented at the bottom of the figure.

Table 2. Lattice parameters and Rietveld refinement result for FeMoTaTiZr alloy

\begin{tabular}{|c|c|c|c|c|c|c|c|c|c|}
\hline \multirow[t]{2}{*}{ Phase } & \multicolumn{3}{|c|}{ Lattice parameters $(\AA)$} & \multirow{2}{*}{$\begin{array}{c}\text { Crystallite } \\
\text { size } \\
(\mathrm{nm})\end{array}$} & \multirow{2}{*}{$\begin{array}{c}\text { Weight } \\
\text { fractions } \\
(\%)\end{array}$} & \multirow[t]{2}{*}{$\begin{array}{l}\text { Space } \\
\text { group }\end{array}$} & \multicolumn{3}{|c|}{$\begin{array}{c}\text { Reliability } \\
\text { factors }\end{array}$} \\
\hline & $a$ & $b$ & $c$ & & & & $\mathbf{R}_{\mathrm{p}}$ & $\mathbf{R}_{\mathrm{wp}}$ & $\boldsymbol{R}_{\exp }$ \\
\hline $\mathrm{Ti}_{2} \mathrm{Fe}$ & $11.336(14)$ & & & 26.7(27) & 39.63 & $\begin{array}{l}\mathrm{Fd}-3 \mathrm{~m} \\
(\mathrm{fcc})\end{array}$ & 5.18 & 8.37 & 1.68 \\
\hline MoTa & $3.2093(40)$ & & & $38.3(51)$ & 23.40 & $\begin{array}{c}\mathrm{Im}-3 \mathrm{~m} \\
(\mathrm{bcc})\end{array}$ & & & \\
\hline Mo & $3.1421(39)$ & & & $28.2(25)$ & 20.68 & $\begin{array}{c}\mathrm{Im}-3 \mathrm{~m} \\
(\mathrm{bcc})\end{array}$ & & & \\
\hline (Fe Mo)Zr & $5.2103(64)$ & & $8.502(11)$ & 28.7(15) & 16.13 & $\begin{array}{c}\text { P63/mmc } \\
\text { (hex) }\end{array}$ & & & \\
\hline $\mathrm{Ti}_{7} \mathrm{Zr}_{3}$ & $2.989(20)$ & & $4.683(97)$ & 70.(16) & 0.16 & $\begin{array}{l}\mathrm{P} 63 / \mathrm{mmc} \\
\text { (hex) }\end{array}$ & & & \\
\hline
\end{tabular}

where:

$R_{P}=\frac{\sum\left|Y_{i}(o b s)-Y_{i}(c a l c)\right|}{\sum Y_{i}(o b s)}, R_{W P}=\left\{\frac{\sum \omega_{i}\left[Y_{i}(o b s)-Y_{i}(\text { calc })\right]^{2}}{\sum \omega_{i}\left[Y_{i}(o b s)\right]^{2}}\right\}^{1 / 2}$

After the indexing, the diffraction data was subjected to Rietveld refinement, Figure 7 showing the Rietveld refinement patterns for the FeMoTaTiZr alloy. The refined lattice parameters and Rietveld refinement results are listed in Table 2. The Rietveld refinement results indicated the presence, along with Mo, of two main crystalline cubic phases of $\mathrm{Ti}_{2} \mathrm{Fe}$ and MoTa. In addition to these main constituents, a hexagonal phase was identified in the alloy - (Fe Mo)Zr - and, in a very small proportion, the compound $\mathrm{Ti} \mathrm{Zr}$ r. This is consistent with the SEM/EDS analysis and elemental mapping results.

\subsection{Morphology and elemental composition of the coatings}

The EDS mapping of consisted elements in the coatings can be observed in Figure 8. The EDS analysis confirmed the presence of $\mathrm{Ca}$ and $\mathrm{P}$ in both coatings. The elements of substrates are also found, due to the small thickness of the coatings. The EDS 
mapping analysis was used to investigate elemental distribution $(\mathrm{Ca}, \mathrm{P}$, and $\mathrm{Zn})$ and the results are showed in Figure 8 . The $\mathrm{Ca} / \mathrm{P}$ ratio of the HAP coating was about 1.70. For the $\mathrm{Zn}$ doped HAP coatings, the $\mathrm{Ca} / \mathrm{P}$ ratio was about 1.96 , while the $\mathrm{Ca} /(\mathrm{P}+\mathrm{Zn})$ ratio was equaled to 1.66. All coatings showed the $\mathrm{Ca} / \mathrm{P}$ ratio close to the value of stoichiometric HAP (1.67), demonstrating that the coatings consisted in a calcium phosphate phase. After $\mathrm{Zn}$ addition, $(\mathrm{Ca} / \mathrm{Zn}+\mathrm{P})$ ratio corresponds to 1.67 , indicating that the coating still exhibited the HAP composition. The EDS mapping showed that each element was well dispersed on the investigated surface, presenting the formation of a homogenous coating (see especially the mapping of $\mathrm{Ca}, \mathrm{P}$ and $\mathrm{Zn}$ elements Figure $8)$. No cracks or other defects were found on the surface. It is well known that the addition of $\mathrm{Zn}$ into HAP matrix induces distortions in its lattice, leading to the Ca-deficient/rich hydroxyapatite, which probably will increase/decrease its solubility and bioactivity [46].

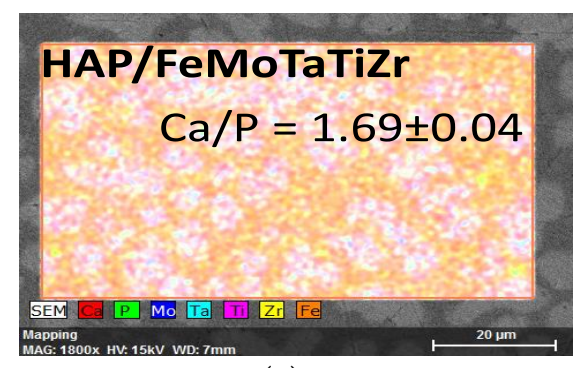

(a)

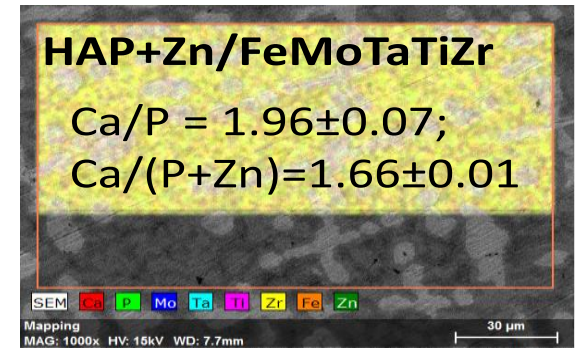

(b)

Figure 8. X-ray energy dispersive spectroscopy (EDS), elemental distribution, and elemental composition of the undoped (a) and Zn-doped hydroxyapatite (b) based coatings.

The morphology of the coatings is displayed in Figure 9. As it is shown in Figure 9, no microcracks can be found on the coatings surfaces. The doped HAP coatings show a variety of agglomerated spherical particles with a wide size distribution (size range of $10-30 \mathrm{~nm}$ ), which are larger than of the HAP crystal found in native bone [47]. It was reported that the smaller particles lead to a higher bioactivity, more proper for biomedical applications [47].

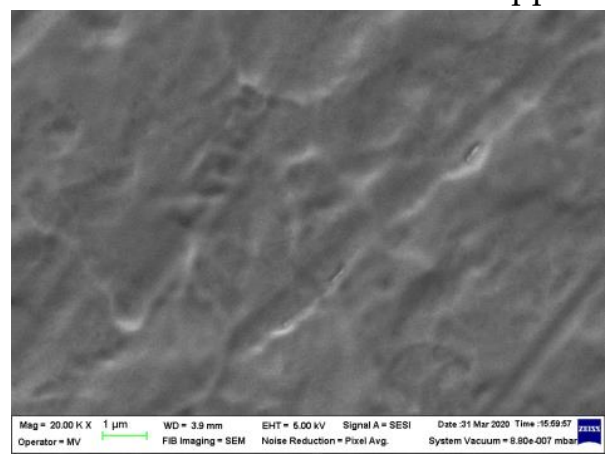

(a)

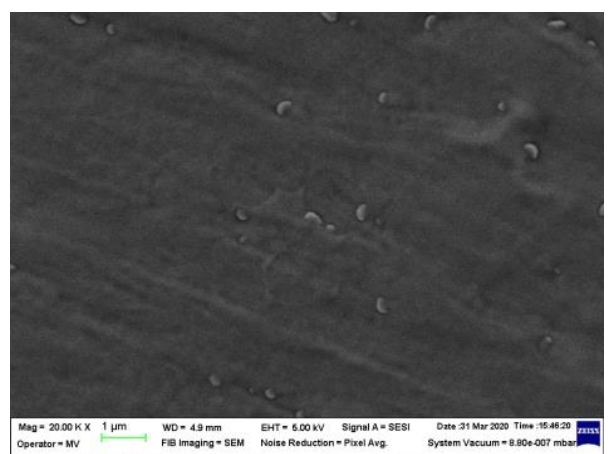

(b)

Figure 9. SEM images of the coatings deposited on metallic FeMoTaTiZr substrates (x20000): (a) (HAP)/FeMoTaTiZr; (b) $(\mathrm{HAP}+\mathrm{Zn}) /$ FeMoTaTiZr.

3.3. Phase composition and chemical binding of the coatings 
The X-ray diffraction patterns of HAP coatings and Zn doped HAP coatings are presented in Figure 10. The identification of the diffraction peaks of HAP was performed using ICDD-The International Centre for Diffraction Data, card no.09-0432. In some cases, it is difficult to sustain that the peaks are those of HAP, because the peaks of alloys were overlapped on those of HAP. The peaks situated between $55.0^{\circ}$ and $80.0^{\circ}$ can be attributed to HAP phase as follows: $55.9^{\circ}$ to (322) plan, $64.1^{\circ}$ to (304), $64.7^{\circ}$ to (511) and $71.3^{\circ}$ to (431). This statement is based on the fact that the grazing experiments were performed at an incident angle of $2^{\circ}$.

For both coatings deposited on FeMoTaTiZr alloy, the peak located at $34.1^{\circ}$ is certainly attributed to HAP. The peaks situated between $36.4^{\circ}$ and $45.4^{\circ}$ can be ascribed both uncoated alloy and coating. The peaks positioned at $55.5^{\circ}$ can be ascribed to HAP with texture after (322) plan, as well as those situated at $57.1^{\circ}, 63.5^{\circ}$, $66.1^{\circ}, 69.6^{\circ}$ and $71.7^{\circ}$ to (313), (510), (422) and (431), respectively. Zn peak was not evident in any of the XRD diffractogram. This lack can be related to a small amount of $\mathrm{Zn}$ into HAP matrix or to a formation of $\mathrm{ZnO}$, phase which is an amorphous phase. The XRD experiments revealed that the HAP phase was formed in all prepared coatings,either doped or undoped.

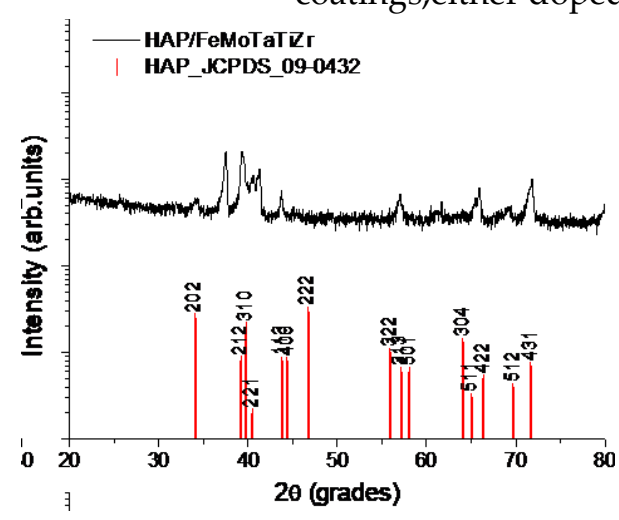

(a)

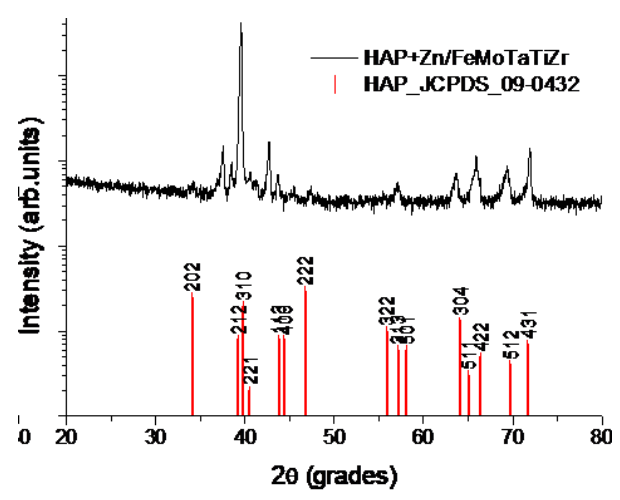

(b)

Figure 10. X-ray diffraction patterns of HAP coatings (a) and Zn doped HAP coatings (b).

The ATR spectra of HAP and HAP+Zn coatings are presented in Figure 11. As it can be noticed, all ATR spectra confirmed the presence of two characteristic functional groups such as phosphate and hydroxyl. In the case of HAP coating, two sharped and well-defined phosphate $v_{3}$ bands can be clearly observed at 1088 and $1025 \mathrm{~cm}^{-1}$, while the phosphate $v_{4}$ bands can be distinguished starting from $618 \mathrm{~cm}^{-1}$ up to $574 \mathrm{~cm}^{-1}$. The band assignments for asymmetric stretching mode of $\mathrm{PO}_{4}{ }^{3-}\left(v_{3}\right)$ and $\mathrm{O}-\mathrm{P}-\mathrm{O}$ bending (v4) are in good agreement with other reported ones [48,49]. By addition of $\mathrm{Zn}$ into the HAP structure, the bands corresponding to $\mathrm{PO}_{4}{ }^{3-}\left(v_{3}\right)$ became wider, but no peak wavenumber shift was revealed. This finding validates the assumption that the $\mathrm{Zn}^{2+}$ ions were successfully introduced into the HAP structure despite the fact that several bands assigned to the functional group of $\mathrm{PO}_{4}{ }^{3-}\left(v_{4}\right)$ exhibited a slightly shift $\left(<15 \mathrm{~cm}^{-1}\right)$ towards higher wavenumbers. The broad bands ranged between $3600 \mathrm{~cm}^{-1}$ and 3500 $\mathrm{cm}^{-1}$ can be attributed to the $\mathrm{O}-\mathrm{H}$ stretching. 


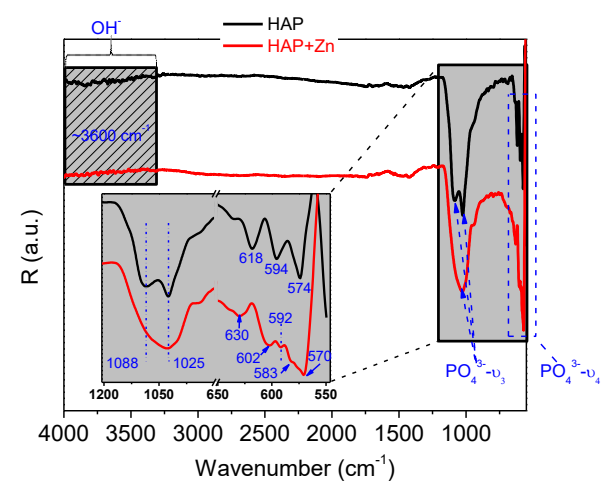

Figure 11. ATR-FTIR spectra of both HAP and HAP+Zn coatings deposited on FeMoTaTiZr alloy.

\subsection{Hardness, elastic modulus, and roughness}

Hardness and elastic modulus of the investigated samples are presented in Table 3, the values were determined according to the Oliver-Pharr method by forcedisplacement curves presented in Figure 12. One may see that the hardness of the alloy is about $10 \mathrm{GPa}$. After the deposition, a decrease in hardness can be found. After the $\mathrm{Zn}$ addition, an increase in hardness was observed for HAP coatings. Thus, it can be noted that the $\mathrm{Zn}$ addition leads to a small increase in HAP hardness. Regarding to the elastic modulus, the investigated alloy exhibited high elastic modulus compared to the coatings. All investigated coatings have similar values of elastic modulus, indicating that the substrate have no influence. Moreover, the $\mathrm{Zn}$ addition decreases the elastic modulus of HAP coatings, a positive result, which can reveal that the Zn based HAP coatings is proper for biomedical applications. The challenge is to obtain materials with the elastic modulus close to the value of human bones [1,5,8,9,18,32]. In Table 3, the $\mathrm{H}^{3} / \mathrm{E}^{2}$ ratio is also calculated, which is related to the resistance to plastic deformation, a parameter sensitive to corrosion properties of the materials [50].

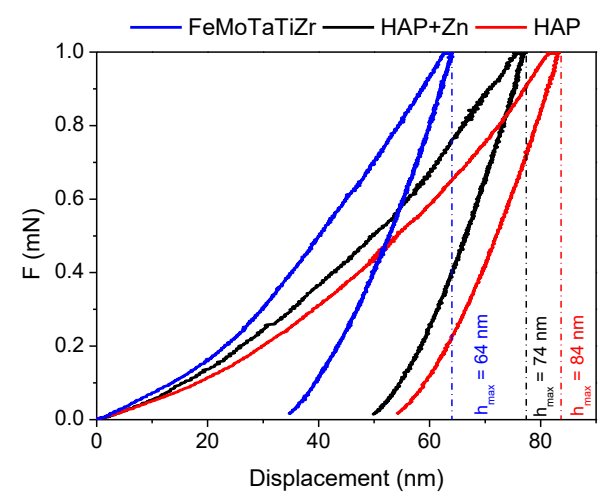

Figure 12. Experimental force-displacement curves of the coated and uncoated FeMoTaTiZr substrate.

The roughness of the investigated surface before corrosion tests is presented in Table 3. The roughness is a parameter very important in clinical practice. For example, the roughness of endosseous dental implants should not exceed the $100 \mu \mathrm{m}$ [51]. On the other hand, it was reported that the bone grows better on the rough implant sur- 
faces, as a result of the high interfaces between bone and implant [52-55]. According to Table 3, the roughness of uncoated substrate increased after coating with HAP, and it was considerably increased by the $\mathrm{Zn}$ addition. A flat surface exhibited the skewness $\left(\mathrm{S}_{\mathrm{k}}\right)$ of about zero, while a positive or negative value means that a surface has few valleys and lots of peaks or few peaks and many valleys, respectively [56]. The Zn doped coating precedes a negative $S_{k}$ value, meaning that the surface consisted of few peaks and lots of valleys. This last finding can be attributed to the polished process applied to the substrate. It can be observed that the uncoated substrates exhibited positive $S_{k}$, with few valleys and lots of peaks. By passing from the positive to negative Sk value after deposition, it can be shown that the peaks were coated, leading to a formation of many sharp peaks with a large valley. However, the value of negative $S_{k}$ in the case of doped coatings was closer to 0 , signifying that this surface has a tendency to become flat.

Table 3. Mechanical properties of doped and undoped HAP coatings deposited on FeMoTaTiZr alloy

\begin{tabular}{cccccccc}
\hline \multirow{2}{*}{ Substrate } & \multirow{2}{*}{ Coating } & \multirow{2}{*}{$\mathrm{Ra}(\mathrm{nm})$} & \multirow{2}{*}{ Skew } & $\mathrm{H}(\mathrm{GPa})$ & $\mathrm{E}(\mathrm{GPa})$ & $\mathrm{H}^{3} / \mathrm{E}^{2}(\mathrm{GPa})$ & $\mathrm{H} / \mathrm{E}$ \\
\hline \multirow{2}{*}{ FeMoTaTiZr } & - & $85.1 \pm 21.1$ & $1.08 \pm 0.10$ & $10.2 \pm 0.5$ & $129.3 \pm 7.7$ & 0.063 & 0.078 \\
\cline { 2 - 8 } & $\mathrm{HAP}$ & $122.3 \pm 37.7$ & $0.65 \pm 0.10$ & $5.5 \pm 0.1$ & $111.9 \pm 6.9$ & 0.013 & 0.049 \\
\cline { 2 - 8 } & $\mathrm{HAP}+\mathrm{Zn}$ & $207.8 \pm 61.5$ & $-0.24 \pm 0.04$ & $6.8 \pm 0.1$ & $108.5 \pm 14.8$ & 0.267 & 0.062 \\
\hline
\end{tabular}

$\left(\mathrm{R}_{\mathrm{a}}, \mathrm{S}_{\mathrm{kew}}\right)$ : roughness parameters, $(\mathrm{H})$ hardness and $(\mathrm{E})$ elastic modulus

\subsection{Electrochemical tests}

In Figure 13, the variation of the open circuit potential (OCP) with time was presented. According to Ref. [57], OCP usually depends on chemical composition of the investigated material, but also on thermomechanical history, the type of electrolyte, temperature etc. Note that the most electropositive potential was recorded by the HAP coating, followed closely by the system, where $\mathrm{Zn}$ was present and then by the uncoated alloy. After only $10 \mathrm{~min}$ of immersion, the HAP+Zn coating formed a protective film, which showed similar values of potential as in the case of HAP. This result can be assigned due to high passivation rate of $\mathrm{Ti}, \mathrm{Zr}$ and $\mathrm{Ta}$ elements [58]. Relatively stable curves were recorded for all investigated systems, showing that the passivating film formed at the metal-electrolyte interface was uniform and protective. The variation of the polarization resistance with time is presented in Figure 14, represented in Tafel coordinates (log $\mathrm{i}-\mathrm{E}$ ), allowing the calculation of some process electrochemical parameters: the corrosion potential $E_{\text {corr }}$ the corrosion current $\mathrm{i}_{\text {corr, }}$ the anodic $b_{a}$ and cathodic $b_{c}$ Tafel slopes, the polarization resistance $R_{p}$, and the corrosion rate $v_{\text {corr. }}$ The behavior and the recorded values for each investigated system were different and they appear to depend on the type of the material. It can be observed that even low $R_{p}$ values were found in the case of $\mathrm{HAP}+\mathrm{Zn}$, the addition of $\mathrm{Zn}$ into HAP composition leading to certain $\mathrm{R}_{\mathrm{p}}$ stability. On the other hand, the HAP coating showed oscillating values when immersed in FBS medium. This can be due to a certain degree of porosity according to Kwok et al., and the corrosion mechanism of HAP coatings can be influenced accordingly [59]. However, considering the high values of 
polarization resistance recorded in this case, it can be said that HAP coatings acted as a more insulating barrier compared to the rest of the investigated systems. The successive increase and drop of $R_{p}$ values in the case of HAP coating can be also related to the nature of substrate. However, when it comes to compositionally complex alloys, it is difficult to evaluate the effect of each component element on the corrosion performance in a certain environment [60]. This result also agrees with the open circuit potential variation, where HAP deposited on FeMoTaTiZr showed the most electropositive value.

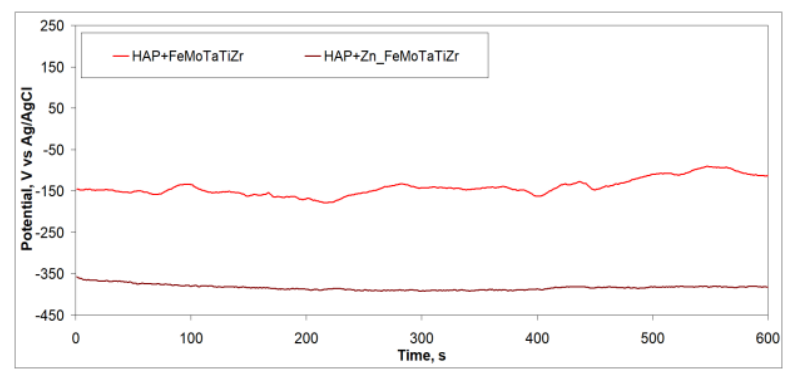

Figure 13. The variation of the open circuit potential with time.

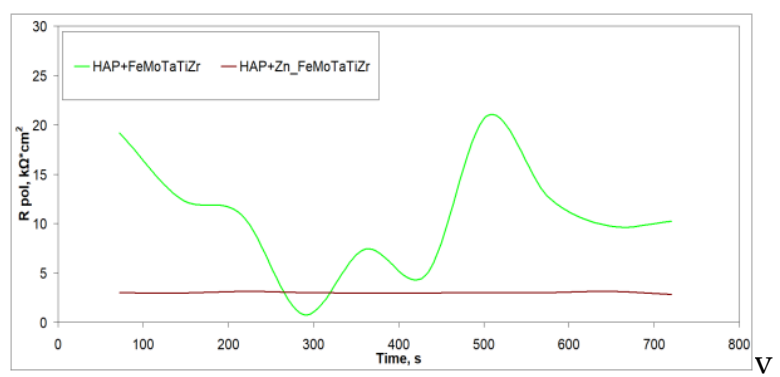

Figure 14. The variation of the polarization resistance with time.

The variation of the corrosion rate with time is presented in Figure 15. This parameter is indicative of the degree, in which a material degrades in a certain medium. Therefore, similar to the previous results, the most resistant material appeared to be HAP. Even though in this case there was also a certain instability, at the end of the test, the next lowest value of the corrosion rate was observed in the case of HAP. Again, the FBS electrolyte also showed in this case a negative influence that led to an accelerated rate of corrosion for $\mathrm{HAP}+\mathrm{Zn}$ materials. Considering the variation of the corrosion rate results, the dissolution of the investigated system at the end of the test followed the order: HAP coating $<\mathrm{HAP}+\mathrm{Zn}$ coating.

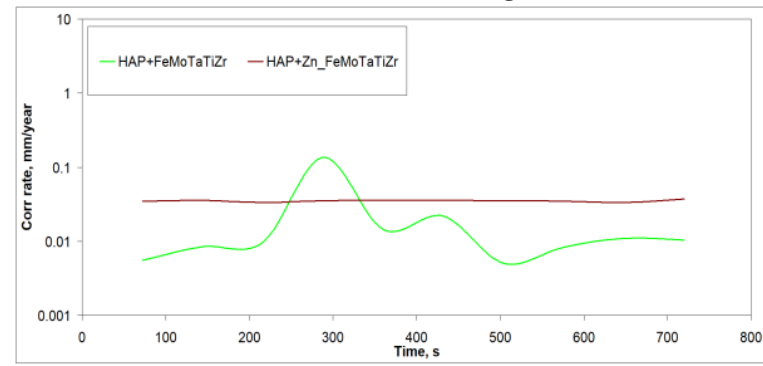

Figure 15. The variation of the corrosion rate with time. 
In Figure 16, the potentiodynamic polarization curves are presented and in Table 4 the kinetic corrosion parameters are shown. Unexpectedly, the corrosion potential presented the least negative value for HAP/FeMoTaTiZr (Ecorr= - $464.5 \mathrm{mV})$, whereas when $\mathrm{Zn}$ was added, the potential dropped to $\mathrm{E}_{\mathrm{corr}}=-935.7 \mathrm{mV}$. Considering the anodic and the cathodic slopes, one can note the higher ba values, therefore a tendency of the investigated materials to passivate [61]. Based on the slopes of each system, the corrosion current density (icorr) is estimated. Lower values were presented by HAP coatings ( $\mathrm{i}_{\text {corr }}=0.0640 \mu \mathrm{A} / \mathrm{cm}^{2}$ ). An increase up to about $3 \mu \mathrm{A} / \mathrm{cm}^{2}$ was estimated for $\mathrm{i}_{\text {corr }}$ in the case of $\mathrm{Zn}$-containing coatings. Higher polarization resistance $\left(\mathrm{R}_{\mathrm{p}}\right)$ and lowest corrosion rate values were ascribed to HAP coating, followed by Zn-containing coatings.

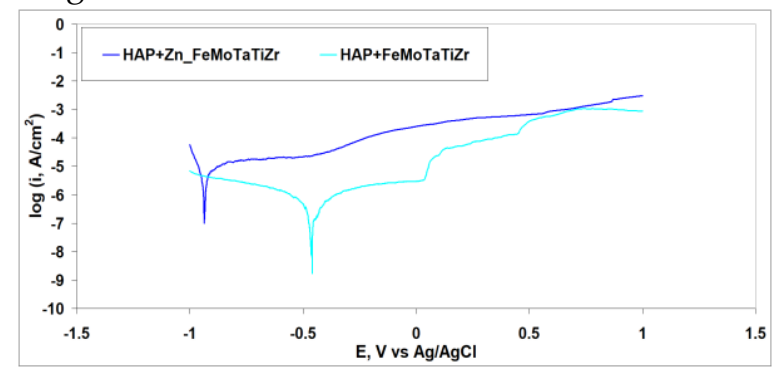

Figure 16. The potentiodynamic polarization curves.

Table 4. The kinetic corrosion parameters

\begin{tabular}{cccccccc}
\hline Coating & Substrate & $\begin{array}{c}E_{\text {corr }} \\
(\mathrm{mV})\end{array}$ & $\begin{array}{c}\mathrm{i}_{\text {corr }} \\
\left(\mu \mathrm{A} / \mathrm{cm}^{2}\right)\end{array}$ & $\begin{array}{c}\mathrm{R}_{\mathrm{p}} \\
\left(\Omega \cdot \mathrm{cm}^{2}\right)\end{array}$ & $\begin{array}{c}\mathrm{b}_{\mathrm{a}} \\
(\mathrm{mV} / \mathrm{dec})\end{array}$ & $\begin{array}{c}\mathrm{b}_{\mathrm{c}} \\
(\mathrm{mV} / \mathrm{dec})\end{array}$ & $\begin{array}{c}v_{\text {corr }} \\
(\mu \mathrm{m} / \text { year })\end{array}$ \\
\hline HAP & FeMoTaTiZr & -464.5 & 0.064 & 803.26 & 64.8 & -30.5 & 0.749 \\
\hline HAP+Zn_FeMoTaTiZr & -935.7 & 3.007 & 4.27 & 109.4 & -52.5 & 35.170 \\
\hline
\end{tabular}

Ecorr - corrosion potential, $\mathrm{i}_{\text {corr }}$ - corrosion current, $\mathrm{b}_{\mathrm{a}}$ - anodic and $\mathrm{b}_{\mathrm{c}}$ - cathodic Tafel slopes, $\mathrm{R}_{\mathrm{p}}$ - polarization resistance, $v_{\text {corr }}$ - corrosion rate

The electrochemical impedance spectroscopy tests were performed over a frequency range of $100 \mathrm{kHz}$ to $2 \mathrm{mHz}$, with a signal amplitude of $10 \mathrm{mV}$ relative to the equilibrium potential. The number of response signal pick-up points per decade was 10. The EIS data for the investigated systems immersed in FBS medium at room temperature are presented in Figures 17 ad 18. The results were presented in terms of Nyquist diagram, where impedance is plotted as a complex number (-Zi vs. Zr). Bode diagram was also employed, where the magnitude of impedance $|Z|$ and the phase angle $\theta$ were plotted against frequency f. The larger semicircle in Nyquist plot is related to a better corrosion resistance. Higher semicircles are found for the HAP coating, followed closely by HAP+Zn deposition (Figure 18.). In Figure 18, a similar impedance modulus was observed for HAP coating in the low frequency region. Lower values of impedance modulus were recorded for $\mathrm{Zn}$ addition HAP depositions. 


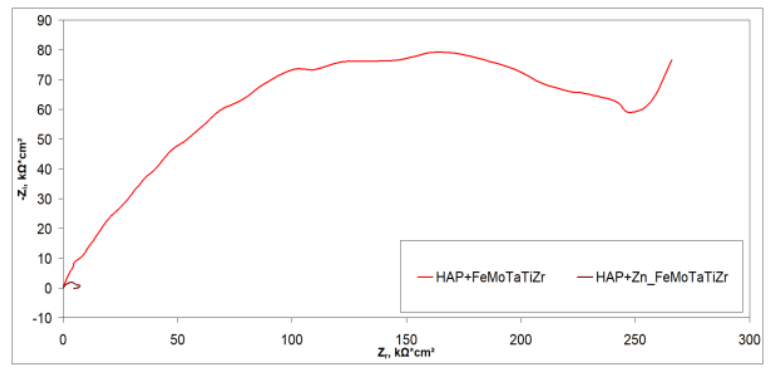

Figure 17. Nyquist diagram

The use of EIS has the main advantage of analyzing the formed interfaces when a material is immersed in an electrolyte, using their frequency response to an applied potential and their corresponding resistive and capacitive behavior. In order to assess the corrosion kinetics present at the interface, the impedance data was used for fitting procedure with an equivalent circuit. In this case, Randles circuit was employed, taking into consideration a charge transfer resistance $\left(R_{p}\right)$ and an ideal capacitor $(C d l)$, which describes the flow of the current at the material/ electrolyte interface [25,62-65]. The previous mentioned parameters are used in parallel and a solution resistance was also added $\left(R_{s}\right)$. The interface is usually characterized by a double-layer formed between the material and the electrolyte and it depends of each type of investigated system and the FBS electroactive species.

Taking into consideration the extracted electrochemical parameters (Table 5), the lowest value of $\mathrm{Cdl}$ was exhibited by HAP coating $\left(1.615 \mu \mathrm{F} / \mathrm{cm}^{2}\right)$. Apparently, adding $\mathrm{Zn}$ increased the value of the capacitance up to $5.213 \mu \mathrm{F} / \mathrm{cm}^{2}$, decreasing the electrochemical properties. Accordingly, the lowest value of $\mathrm{R}_{\mathrm{p}}$ parameter was also indicated by this system $\left(7.631 \mathrm{k} \Omega \cdot \mathrm{cm}^{2}\right)$. A higher polarization resistance is preferred, and in this case $\mathrm{Zn}$ free HAP depositions showed around $300 \mathrm{k} \Omega \cdot \mathrm{cm}^{2}$. When it comes to Rs, the most unstable material in FBS medium appeared to be HAP+Zn coating $\left(55.530 \Omega \cdot \mathrm{cm}^{2}\right)$, whereas the most electropositive value of Eeq was shown by the same system without $\mathrm{Zn}$ addition $(-84 \mathrm{mV})$. However, in a recent study [66], Zn proved to be efficient for in vitro degradation as well as for cytotoxicity assay in this medium (FBS). Moreover, $\mathrm{Zn}$ tuned BMs showed a great potential for biomedical applications. In another study [67], Zn based biodegradable composites with 3 and 5 wt. \% hydroxyapatite were investigated in simulated body fluid and were found to be biocompatible.

In Figure 19,the investigated surfaces are presented after electrochemical tests. One may note that all coatings were affected by FBS electrolyte. The HAP coatings were partially delaminated after electrochemical tests. Moreover, on the surface of HAP, there are some crystals deposited, attributed to the crystals from the FBS electrolyte. Regarding the Zn doped HAP coatings, different particles were found, which can be related to the protein layer formed from the FBS solution and no cracks of coatings were found. Contu et al. reported that these protein layers could increase the activity of the anodic process and decrease it in the cathodic process [68]. According to SEM images, both undoped and doped HAP have proper corrosion resistance in FBS electrolyte. 


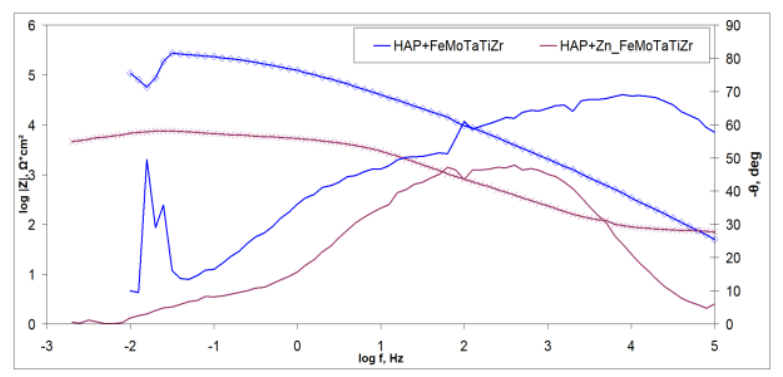

Figure 18. Bode diagram.

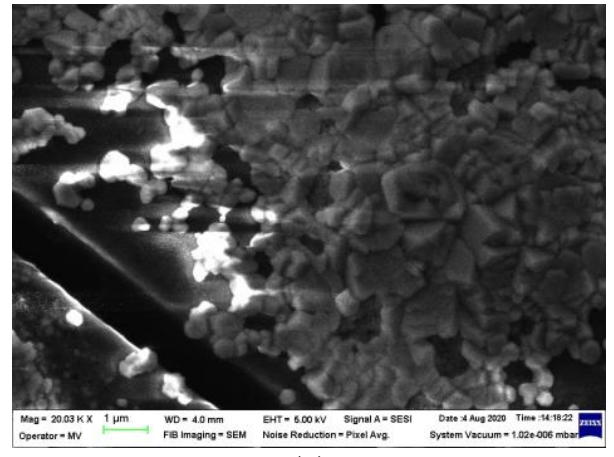

(a)

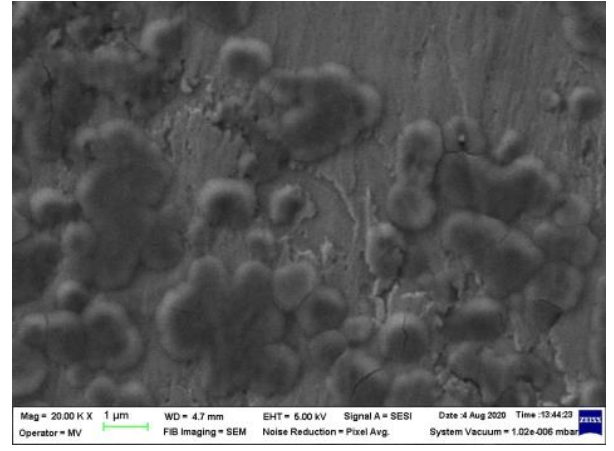

(b)

Figure 19. SEM images of the coatings deposited on metallic FeMoTaTiZr substrate at the end of corrosion tests (x20000): (a) HAP/FeMoTaTiZr; (b) (HAP+Zn)/FeMoTaTiZr.

Table 5. The EIS electrochemical parameters

\begin{tabular}{clcccc}
\hline Coating & Substrate & $\begin{array}{c}\text { Eeq } \\
(\mathrm{mV})\end{array}$ & $\begin{array}{c}\mathrm{R}_{\mathrm{s}} \\
\left(\mathrm{U} \cdot \mathrm{cm}^{2}\right)\end{array}$ & $\begin{array}{c}\mathrm{R}_{\mathrm{p}} \\
\left(\mathrm{kU} \cdot \mathrm{cm}^{2}\right)\end{array}$ & $\begin{array}{c}\mathrm{C}_{\mathrm{dl}} \\
\left(\mu \mathrm{F} / \mathrm{cm}^{2}\right)\end{array}$ \\
\hline HAP & FeMoTaTiZr & -84 & 338.000 & 311.200 & 1.615 \\
\hline HAP+Zn & FeMoTaTiZr & -380 & 55.530 & 7.631 & 5.213 \\
\hline
\end{tabular}

\section{Conclusions}

According to the gained results, the following conclusions can be drawn:

\section{FeMoTaTiZr Alloy}

- $\quad$ The high entropy alloys from the FeMoTaTiZr alloying system can be obtained using the VAR method, after performing multiple remelting, because the chemical elements have high melting temperatures. Homogeneity of the alloy has been proven by the concordance between the designed compositions and EDS chemical analysis performed on the mini-ingots. During the metallurgical process the metal losses are very small, due to the high vacuum level and protective argon atmosphere.

- $\quad$ The SEM analysis and the elemental mapping showed that the microstructure of the cast FeMoTaTiZr alloy consists in dendrites based on Mo and Ta, dispersed in matrix formed by $\mathrm{Ti}, \mathrm{Fe}$, and $\mathrm{Zr}$.

- $\quad$ The structural characterization of FeMoTaTiZr alloy, performed by X-ray diffraction, confirmed the results of elemental mapping and SEM, EDS investigations, related to the MoTa based dendrites and offered supplementary details; in the matrix 
of the FeMoTaTiZr alloy three constituents coexist: $\left(\mathrm{Ti}_{7} \mathrm{Zr}_{3}\right)_{0.2}$, $\mathrm{Ti}_{2} \mathrm{Fe}$ and a phase based on FeZr.

- $\quad$ The Rietveld refinement results indicated the presence, along with Mo, of two main crystalline cubic phases of $\mathrm{Ti}_{2} \mathrm{Fe}$ and MoTa.

\section{Undoped and Doped Coatings}

- $\quad$ The EDS analysis confirmed the presence of $C a$ and $P$ in both coatings with $\mathrm{Ca} /(\mathrm{P}+\mathrm{Zn})$ ratio of about 1.70 for undoped HAP and of about 1.66 for $\mathrm{Zn}$ doped HAP coatings.

- $\quad$ No cracks or other defects were found on the surface.

- $\quad$ The XRD and ATR experiments revealed that the HAP phase was formed in all prepared coatings, either doped or undoped.

- The roughness of uncoated substrates increased after coating with HAP, and it was considerably increased by the $\mathrm{Zn}$ addition.

- $\quad$ After the $\mathrm{Zn}$ addition, an increase in hardness was observed for HAP coatings.

- $\quad$ High values of polarization resistance recorded for HAP coatings, indicating that HAP coatings acted as a more insulating barrier.

- The dissolution of the investigated system at the end of the electrochemical tests followed the order: HAP/FeMoTaTiZr alloy $<(\mathrm{HAP}+\mathrm{Zn}) / \mathrm{FeMoTaTiZr}$ alloy.

- The lowest corrosion rate was observed in the case of HAP, indicating that the FBS electrolyte accelerated rate of corrosion for HAP+Zn materials.

The present study succeeded in the preparation of HAP, while the $\mathrm{Zn}$ addition leads to a high dissolution rate in FBS solution. Thus, it can be concluded that the $\mathrm{Zn}$ doped HAP coatings can be used as biodegradable materials in medical applications.

Author Contributions: Conceptualization, M.M.C. and A.V.; methodology, M.M.C., V.G. and A.V.; investigation, M.M.C. (alloy and coatings characterization of corrosion resistance), A.V. (coatings preparation and characterization of SEM, EDS), V.G.(alloy preparation and characterization), I.V.(alloy preparation and characterization), M.D.(XRD analyses), I.P. (nanoindentation and ATR tests), A.E.K. (preparation of the coatings); D.P. (X-ray diffraction and Rietveld analysis of alloy); V.E.M. (alloy characterization by SEM, EDS, elemental mapping), and M.I. (electrochemical measurements, including EIS, potentiodynamic polarization, RP vs time, Corr rate vs time, OCP); validation, M.M.C. and A.V.; writing-original draft preparation, A.V., writing - review and editing, M.M.C., A.V., V.G, I.V., and V.B.; visualization, M.M.C. and A.V.; supervision, M.M.C. and A.V.; project administration, M.M.C., A.V., V.G. and I.V. All authors have read and agreed to the published version of the manuscript.

Funding: Work supported under the following research projects: PN-IIIP1-1.2-PCCDI-2017-0239/60PCCDI 2018, within PNCDI III of the Romanian National Authority for Scientific Research (CNCS - UEFISCDI) and Romanian National Core Program no. 18N-0102/2019.

Acknowledgments: I.V. and V.G want to mention that the alloys based on FeMoTaTiZr system were obtained using the MRF ABJ 900 vacuum arc remelting equipment placed at ERAMET Laboratory, Faculty of Science and Engineering Materials from University Politehnica of Bucharest, Romania. A.V. thanks to European Regional Development Fund through Competitiveness Operational Programme 2014-2020, Action 1.1.3 Creating synergies with H2020 Programme, project H2020 Support Center for European project management and European promotion, MYSMIS code 107874. A.V. also thanks to Tomsk Polytechnic University within the framework of the Tomsk Polytechnic University-Competitiveness Enhancement Program grant.

Conflicts of Interest: The authors declare no conflict of interest. 


\section{References}

1. Yeh, J.W.; Chen, S.K.; Lin, S.J.; Gan, J.Y.; Chin, T.S.; Shun, T.T.; Tsau, C.H.; Chang, S.Y. Nanostructured high-entropy alloys with multiple principal elements: Novel alloy design concepts and outcomes. Adv. Eng. Mater. 2004, 6, 299-303, doi:10.1002/adem.200300567.

2. Miracle, D.B. Critical Assessment 14: High entropy alloys and their development as structural materials. Mater. Sci. Technol. 2015, 31, 1142-1147.

3. Chen, Q.; Thouas, G.A. Metallic implant biomaterials. Mater. Sci. Eng. R Reports 2015, 87, 2015, 1-57.

4. Verestiuc, L.; Spataru, M.C.; Baltatu, M.S.; Butnaru, M.; Solcan, C.; Sandu, A.V.; Voiculescu, I.; Geanta, V. New Ti-Mo-Si materials for bone prosthesis applications. J. Mech. Behav. Biomed. Mater. 2020, 113, 104198.

5. Niinomi, M. Biologically and Mechanically Biocompatible Titanium Alloys. Mater. Trans. 2008, 49, $2170-2178$.

6. M., G.; A.K., S.; R., A.; A.K., G. Ti based biomaterials, the ultimate choice for orthopaedic implants - A review. Mater. Sci. Forum 2099, 54, 397-425.

7. Geanta, V.; Chereches, T.; Lixandru, P.; Voiculescu, I.; Stefanoiu, R.; Dragnea, D.; Zecheru, T.; Matache, L. Virtual Testing of Composite Structures Made of High Entropy Alloys and Steel. Metals (Basel). 2017, 7, 496.

8. Geanta, V.; Voiculescu, I.; Kelemen, H.; Manu, D.; Molnar, G.; Kelemen, G. Mg-Ca-Zn bio-degradable light alloys produced in a levitation induction melting furnace. Int. J. Appl. Electromagn. Mech. 202AD, 63, S69-S78.

9. Constantin, G.; Balan, E.; Voiculescu, I.; Geanta, V.; Craciun, V. Cutting behavior of Al0.6CoCrFeNi High Entropy Alloy. Materials (Basel). 2020, 13, 4181.

10. Breme, H.J.; Biehl, V.; Helsen, J.A. Metals and implants. In Metals as Biomaterials; Helsen, J.A., Breme, H.J., Eds.; John Wiley and Sons Ltd: Chichester, UK, 1998; pp. 37-71 ISBN 0471969354.

11. Xin, S.W.; Zhang, M.; Yang, T.T.; Zhao, Y.Y.; Sun, B.R.; Shen, T.D. Ultrahard bulk nanocrystalline VNbMoTaW high-entropy alloy. J. Alloys Compd. 2018, 769, 597-604, doi:10.1016/j.jallcom.2018.07.331.

12. Oliveira, N.T.C.; Guastaldi, A.C. Electrochemical stability and corrosion resistance of Ti-Mo alloys for biomedical applications. Acta Biomater. 2009, 5, 399-405, doi:10.1016/j.actbio.2008.07.010.

13. Martins, J.R.S.; Nogueira, R.A.; De Araújo, R.O.; Donato, T.A.G.; Arana-Chavez, V.E.; Claro, A.P.R.A.; Moraes, J.C.S.; Buzalaf, M.A.R.; Grandini, C.R. Preparation and characterization of Ti-15Mo alloy used as biomaterial. Mater. Res. 2011, 14, 107-112, doi:10.1590/S1516-14392011005000013.

14. Bobyn, J.D.; Stackpool, G.J.; Hacking, S.A.; Tanzer, M.; Krygier, J.J. Characteristics of bone ingrowth and interface mechanics of a new porous tantalum biomaterial. J. Bone Jt. Surg. - Ser. B 1999, 81, 907-914, doi:10.1302/0301-620X.81B5.9283.

15. Black, J. Biologic performance of tantalum. Clin. Mater. 1994, 16, 167-173.

16. Gordin, D.M.; Gloriant, T.; Nemtoi, G.; Chelariu, R.; Aelenei, N.; Guillou, A.; Ansel, D. Synthesis, structure and electrochemical behavior of a beta Ti-12Mo-5Ta alloy as new biomaterial. Mater. Lett. 2005, 59, 2936-2941, doi:10.1016/j.matlet.2004.09.063.

17. Zhou, S.; Liang, Y.J.; Zhu, Y.; Jian, R.; Wang, B.; Xue, Y.; Wang, L.; Wang, F. High entropy alloy: A promising matrix for high-performance tungsten heavy alloys. J. Alloys Compd. 2019, 777, 1184-1190, doi:10.1016/j.jallcom.2018.11.089.

18. Todai, M.; Nagase, T.; Hori, T.; Matsugaki, A.; Sekita, A.; Nakano, T. Novel TiNbTaZrMo high-entropy alloys for metallic biomaterials. Scr. Mater. 2017, 129, 65-68, doi:10.1016/j.scriptamat.2016.10.028.

19. Nomura, N. Zirconium Alloys for Orthopedic Applications. In; Springer, Berlin, Heidelberg, 2015; pp. $215-221$.

20. Mehjabeen, A.; Song, T.; Xu, W.; Tang, H.P.; Qian, M. Zirconium Alloys for Orthopaedic and Dental Applications. Adv. Eng. Mater. 2018, 20, 1800207, doi:10.1002/adem.201800207.

21. Fini, M.; Giavaresi, G.; Torricelli, P.; Borsari, V.; Giardino, R.; Nicolini, A.; Carpi, A. Osteoporosis and biomaterial osteointegration. Biomed. Pharmacother. 2004, 58, 487-493, doi:10.1016/j.biopha.2004.08.016. 
A primer for non-biologists. Front. Mater. 2016, 3, 40, doi:10.3389/fmats.2016.00040.

23. Katti, K.S. Biomaterials in total joint replacement. Colloids Surfaces B Biointerfaces 2004, 39, 133-142, doi:10.1016/j.colsurfb.2003.12.002.

24. Eliaz, N. Corrosion of metallic biomaterials: A review. Materials (Basel). 2019, 12, 407, doi:10.3390/ma12030407.

25. Wilson, J. Metallic biomaterials; 2018; ISBN 9780081022054.

26. Katti, K.S. Biomaterials in total joint replacement. Colloids Surfaces B Biointerfaces 2004, 39, $133-142$.

27. Chen, Q.; Thouas, G.A. Metallic implant biomaterials. Mater. Sci. Eng. R Reports 2015, 87, 1-57, doi:10.1016/j.mser.2014.10.001.

28. Prasad, K.; Bazaka, O.; Chua, M.; Rochford, M.; Fedrick, L.; Spoor, J.; Symes, R.; Tieppo, M.; Collins, C.; Cao, A.; et al. Metallic biomaterials: Current challenges and opportunities. Materials (Basel). 2017, 10, 884, doi:10.3390/ma10080884.

29. Bauer, S.; Schmuki, P.; von der Mark, K.; Park, J. Engineering biocompatible implant surfaces: Part I: Materials and surfaces. Prog. Mater. Sci. 2013, 58, 261-326, doi:10.1016/j.pmatsci.2012.09.001.

30. Okazaki, Y.; Gotoh, E. Metal release from stainless steel, Co-Cr-Mo-Ni-Fe and Ni-Ti alloys in vascular implants. Corros. Sci. 2008, 50, 3429-3438, doi:10.1016/j.corsci.2008.09.002.

31. Behera, D.R.; Nayak, P.; Rautray, T.R. Phosphatidylethanolamine impregnated Zn-HA coated on titanium for enhanced bone growth with antibacterial properties. J. King Saud Univ. - Sci. 2020, 32, 848-852, doi:10.1016/j.jksus.2019.03.004.

32. Bai, X.; Lin, C.; Wang, Y.; Ma, J.; Wang, X.; Yao, X.; Tang, B. Preparation of Zn doped mesoporous silica nanoparticles (Zn-MSNs) for the improvement of mechanical and antibacterial properties of dental resin composites. Dent. Mater. 2020, 36, 794-807, doi:10.1016/j.dental.2020.03.026.

33. Wang, Y.; Zhao, S.; Li, G.; Zhang, S.; Zhao, R.; Dong, A.; Zhang, R. Preparation and in vitro antibacterial properties of anodic coatings co-doped with $\mathrm{Cu}, \mathrm{Zn}$, and $\mathrm{P}$ on a Ti-6Al-4V alloy. Mater. Chem. Phys. 2020, 241, 122360, doi:10.1016/j.matchemphys.2019.122360.

34. Bodhak, S.; Bose, S.; Bandyopadhyay, A. Bone cell-material interactions on metal-ion doped polarized hydroxyapatite. Mater. Sci. Eng. C 2011, 31, 755-761, doi:10.1016/j.msec.2011.01.003.

35. Vladescu, A.; Mihai Cotrut, C.; Ak Azem, F.; Bramowicz, M.; Pana, I.; Braic, V.; Birlik, I.; Kiss, A.; Braic, M.; Abdulgader, R.; et al. Sputtered Si and Mg doped hydroxyapatite for biomedical applications. Biomed. Mater. 2018, 13, 025011, doi:10.1088/1748-605X/aa9718.

36. Vladescu, A.; Braic, M.; Azem, F.A.; Titorencu, I.; Braic, V.; Pruna, V.; Kiss, A.; Parau, A.C.; Birlik, I. Effect of the deposition temperature on corrosion resistance and biocompatibility of the hydroxyapatite coatings. Appl. Surf. Sci. 2015, 354, 373-379, doi:10.1016/j.apsusc.2015.05.059.

37. Azem, F.A.; Birlik, I.; Braic, V.; Toparli, M.; Celik, E.; Parau, A.; Kiss, A.; Titorencu, I.; Vladescu, A. Effect of SiC interlayer between Ti6Al4V alloy and hydroxyapatite films. Proc. Inst. Mech. Eng. Part H J. Eng. Med. 2015, 229, 307-18, doi:10.1177/0954411915578886.

38. Dinu, M.; Kiss, A.E.; Parau, A.C.; Braic, V.; Vitelaru, C.; Braic, M.; Pana, I.; Balaceanu, M.; Vladescu, A. Influence of thermal treatment on the roughness, corrosion resistance and wettability of hydroxyapatite films deposited by RF magnetron sputtering. Key Eng. Mater. 2014, 587, 297-302, doi:10.4028/www.scientific.net/KEM.587.297.

39. Dudin, S.; Cotrut, C.M.; Dinu, M.; Zykova, A.; Parau, A.C.; Yakovin, S.; Vladescu, A. Comparative study of the hydroxyapatite coatings prepared with/without substrate bias. Ceram. Int. 2017, 43, 14968-14975, doi:10.1016/j.ceramint.2017.08.016.

40. Secchi, V.; Franchi, S.; Dettin, M.; Zamuner, A.; Beranová, K.; Vladescu, A.; Battocchio, C.; Graziani, V.; Tortora, L.; Iucci, G. Hydroxyapatite surfaces functionalized with a self-assembling peptide: XPS, rairs and nexafs study. Nanomaterials 2020, 10, 1151, doi:10.3390/nano10061151.

41. Vladescu, A.; Padmanabhan, S.C.; Ak Azem, F.; Braic, M.; Titorencu, I.; Birlik, I.; Morris, M.A.; Braic, V. Mechanical properties and biocompatibility of the sputtered Ti doped hydroxyapatite. J. Mech. Behav. Biomed. Mater. 2016, 63, 314-325, 
doi:10.1016/j.jmbbm.2016.06.025.

42. Parau, A.C.; Kiss, A.E.; Braic, V.; Balaceanu, M.; Pana, I.; Vladescu, A. Effect of thermal treatment on the surface morphology and wettability of hydroxyapatite films deposited by rf magnetron sputtering. J. Optoelectron. Adv. Mater. 2012, 14, 1047-1052.

43. Pana, I.; Vitelaru, C.; Kiss, A.; Zoita, N.C.; Dinu, M.; Braic, M. Design, fabrication and characterization of TiO2-SiO2 multilayer with tailored color glazing for thermal solar collectors. Mater. Des. 2017, doi:10.1016/j.matdes.2017.05.063.

44. ISO 25178-601 Geometrical product specifications ( GPS ) - Surface texture : Areal Part 601 : Nominal characteristics of contact (stylus) instruments. ISO 2010.

45. Zhang, Y.; Xing, Q.-W. High Entropy Alloys - Manufacturing Route. In Encyclopedia of Materials: Metals and Alloys; 2020; p. 12123.

46. Blazutti Marçal, R.L.S.; Muniz Ferreira, J.R.; Louro, L.H.L.; Costa, A.M.; Navarro Da Rocha, D.; De Campos, J.B.; Prado Da Silva, M.H. Apatite coatings from ostrich eggshell and its bioactivity assessment. Key Eng. Mater. 2017, 720, 185-188, doi:10.4028/www.scientific.net/KEM.720.185.

47. Doostmohammadi, A.; Monshia, A.; Salehic, R.; Fathia, M.H.; Seyedjafarid, E.; Shafieee, A.; Soleimanif, M. Cytotoxicity evaluation of $63 \mathrm{~S}$ bioactive glass and bone-derived hydroxyapatite particles using human bone-marrow stem cells. Biomed. Pap. 2011, 155, 323-326, doi:10.5507/bp.2011.028.

48. Ren, F.; Ding, Y.; Leng, Y. Infrared spectroscopic characterization of carbonated apatite: A combined experimental and computational study. J. Biomed. Mater. Res. - Part A 2014, 102, 496-505, doi:10.1002/jbm.a.34720.

49. Rehman, I.; Bonfield, W. Characterization of hydroxyapatite and carbonated apatite by photo acoustic FTIR spectroscopy. J. Mater. Sci. Mater. Med. 1997, 8, 1-4, doi:10.1023/A:1018570213546.

50. Pauleau, Y.; Thièry, F. Deposition and characterization of nanostructured metal/carbon composite films. Surf. Coatings Technol. 2004, doi:10.1016/j.surfcoat.2003.10.077.

51. Lang, N.P.; Lindhe, J. Clinical Periodontology and Implant Dentistry, 2 Volume Set, 6th Edition; 2015; ISBN 978-0-470-67248-8.

52. Buser, D.; Schenk, R.K.; Steinemann, S.; Fiorellini, J.P.; Fox, C.H.; Stich, H. Influence of surface characteristics on bone integration of titanium implants. A histomorphometric study in miniature pigs. J. Biomed. Mater. Res. 1991, 25, 889-902, doi:10.1002/jbm.820250708.

53. Gotfredson, K.; Wennerberg, A.; Johansson, C.; Skovgaard, L.T.; Hjørting-Hansen, E. Anchorage of TiO2-blasted, HAcoated, and machined implants: An experimental study with rabbits. J. Biomed. Mater. Res. 1995, 29, 1223-1231, doi:10.1002/jbm.820291009.

54. de Lange, G.L.; Donath, K. Interface between bone tissue and implants of solid hydroxyapatite or hydroxyapatite-coated titanium implants. Biomaterials 1989, 10, 121-125, doi:10.1016/0142-9612(89)90044-6.

55. Puleo, D.A.; Nanci, A. Understanding and controlling the bone-implant interface. Biomaterials 1999, 20, 2311-2321, doi:10.1016/S0142-9612(99)00160-X.

56. Gadelmawla, E.S.; Koura, M.M.; Maksoud, T.M.A.; Elewa, I.M.; Soliman, H.H. Roughness parameters. J. Mater. Process. Technol. 2002, 123, 133-145, doi:10.1016/S0924-0136(02)00060-2.

57. Zuñiga-Diaz, K.; Arrieta-Gonzalez, C.D.; Porcayo-Calderon, J.; Gonzalez-Rodriguez, J.G.; Casales-Diaz, M.; Martinez-Gomez, L. Electrochemical behavior of austenitic stainless steels exposed to acetic acid solution. Int. J. Electrochem. Sci. 2020, 15, 1242 - 1263, doi:10.20964/2020.02.13.

58. Raducanu, D.; Vasilescu, E.; Cojocaru, V.D.; Cinca, I.; Drob, P.; Vasilescu, C.; Drob, S.I. Mechanical and corrosion resistance of a new nanostructured Ti-Zr-Ta-Nb alloy. J. Mech. Behav. Biomed. Mater. 2011, 4, 1421-1430, doi:10.1016/j.jmbbm.2011.05.012.

59. Kwok, C.T.; Wong, P.K.; Cheng, F.T.; Man, H.C. Characterization and corrosion behavior of hydroxyapatite coatings on Ti6Al4V fabricated by electrophoretic deposition. Appl. Surf. Sci. 2009, 255, 6736-6744, doi:10.1016/j.apsusc.2009.02.086.

60. Qiu, Y.; Thomas, S.; Gibson, M.A.; Fraser, H.L.; Birbilis, N. Corrosion of high entropy alloys. npj Mater. Degrad. 2017, 1, 15, 
doi:10.1038/s41529-017-0009-y.

61. Mordyuk, B.N.; Prokopenko, G.I.; Vasylyev, M.A.; Iefimov, M.O. Effect of structure evolution induced by ultrasonic peening on the corrosion behavior of AISI-321 stainless steel. Mater. Sci. Eng. A 2007, 458, 253-261, doi:10.1016/j.msea.2006.12.049.

62. Córdoba-Torres, P. Relationship between constant-phase element (CPE) parameters and physical properties of films with a distributed resistivity. Electrochim. Acta 2017, doi:10.1016/j.electacta.2016.12.087.

63. Hirschorn, B.; Orazem, M.E.; Tribollet, B.; Vivier, V.; Frateur, I.; Musiani, M. Determination of effective capacitance and film thickness from constant-phase-element parameters. Electrochim. Acta 2010, doi:10.1016/j.electacta.2009.10.065.

64. Bredar, A.R.C.; Chown, A.L.; Burton, A.R.; Farnum, B.H. Electrochemical Impedance Spectroscopy of Metal Oxide Electrodes for Energy Applications. ACS Appl. Energy Mater. 2020.

65. Zhou, H.; Bhaduri, S.B. The translatory aspects of calcium phosphates for orthopedic applications. In Biomaterials in Translational Medicine: A Biomaterials Approach; 2018 ISBN 9780128134771.

66. Li, P.; Schille, C.; Schweizer, E.; Kimmerle-Müller, E.; Rupp, F.; Heiss, A.; Legner, C.; Klotz, U.E.; Geis-Gerstorfer, J.; Scheideler, L. Selection of extraction medium influences cytotoxicity of zinc and its alloys. Acta Biomater. 2019, doi:10.1016/j.actbio.2019.03.013.

67. Pathak, D.K.; Pandey, P.M. Evaluation of in vitro corrosion behavior of zinc-hydroxyapatite and zinc-hydroxyapatiteiron as biodegradable composites. J. Biomed. Mater. Res. - Part B Appl. Biomater. 2021, doi:10.1002/jbm.b.34712.

68. Contu, F.; Elsener H Bhni, B. Characterization of implant materials in fetal bovine serum and sodium sulfate by electrochemical impedance spectroscopy. I. Mechanically polished samples. J. Biomed. Mater. Res. 2002, doi:10.1002/jbm.10329. 